\title{
Expression of CREPT is associated with poor prognosis of patients with renal cell carcinoma
}

\author{
HUAQI YIN $^{1 *}$, QINGFEI CAO ${ }^{2 *}$, HAIYUE ZHAO $^{1}$, SHENHENG WANG $^{1}$, WEINAN CHEN $^{1}$, \\ XIAOWEI ZHANG ${ }^{1}$, ZHIJIE CHANG ${ }^{3}$, TAO XU $^{1 *}$ and XIONGJUN YE ${ }^{1,4}$ \\ ${ }^{1}$ Department of Urology, Peking University People's Hospital, The Second Clinical Medical College of Peking University, \\ Beijing 100044; ${ }^{2}$ Department of Urology, The First Affiliated Hospital of Jinzhou Medical University, \\ Jinzhou, Liaoning 121001; ${ }^{3}$ State Key Laboratory of Membrane Biology, School of Medicine, Tsinghua University, \\ Beijing 100084; ${ }^{4}$ Urology and Lithotripsy Center, Peking University People's Hospital, \\ The Second Clinical Medical College of Peking University, Beijing 100044, P.R. China
}

Received October 7, 2018; Accepted July 11, 2019

DOI: $10.3892 / \mathrm{ol} .2019 .10831$

\begin{abstract}
Cell-cycle-associated and expression-elevated protein in tumor (CREPT) functions as a cell cycle modulator that enhances the transcription of cyclin D1 by interacting with RNA polymerase II. CREPT has been identified to be overexpressed in various human cancer types; however, the expression and significance of CREPT in renal cell carcinoma ( $\mathrm{RCC}$ ) has remained largely elusive. In the present study, increased expression of CREPT was identified in 46.7\% RCC tissues compared with adjacent normal tissue (31.1\%; $\mathrm{P}=0.032$ ) using immunohistochemistry. Furthermore, overexpression of CREPT was significantly associated with the Tumor-Node-Metastasis stage $\left(\chi^{2}=11.967, \mathrm{P}=0.001\right)$ and Fuhrman grade $\left(\chi^{2}=15.453, \mathrm{P}<0.001\right)$. In addition, increased expression of CREPT was associated with poor overall survival $(\mathrm{P}=0.021)$ and disease-free survival $(\mathrm{P}=0.015)$ of patients according to Kaplan-Meier analysis. Cellular function assays demonstrated that knockdown of CREPT in the 786-O and 769P RCC cell lines suppressed their proliferative, colony formation, migratory and invasive capacity and led to cell cycle arrest in the G1 phase. In addition, the western blotting analysis demonstrated that CREPT may control the cell cycle through downregulation of cyclin D1 and c-myc. Collectively, the overexpression of CREPT was indicated to be a negative
\end{abstract}

Correspondence to: Dr Tao Xu or Xiongjun Ye, Department of Urology, Peking University People's Hospital, The Second Clinical Medical College of Peking University, 11 Xi Zhi Men Nan Street, Beijing 100044, P.R. China

E-mail: xutao@pkuph.edu.cn

E-mail: yexiongjun@163.com

${ }^{*}$ Contributed equally

Key words: renal cell carcinoma, cell-cycle-related and expression-elevated protein in tumor, proliferation, cyclin D1, c-myc, prognosis prognostic factor for RCC, and CREPT may serve as a novel therapeutic target for the treatment of RCC.

\section{Introduction}

Renal cell carcinoma (RCC) is a cancer that originates from the proximal tubular epithelium, and $70-80 \%$ of RCC cases are clear cell RCC (1). Each year, approximately 200,000 patients are newly diagnosed with RCC and approximately 100,000 succumb to this malignancy, while the incidence of the disease has been steadily increasing in recent years $(2,3)$. It was estimated that almost $25 \%$ of patients present with metastases at diagnosis (4). Surgical resection is a potentially curative therapeutic method for early and localized RCC; however, $>30 \%$ of patients with RCC develop metastases after radical nephrectomy (5). In addition, the 10 -year relative overall survival rates are poor (6). Therefore, exploring biomarkers associated with tumorigenesis and progression may improve the potential therapeutic strategies and the prognosis of RCC.

Expression of the human gene cell cycle-related and expression-elevated protein in tumor (CREPT), also named regulation of nuclear pre-mRNA domain-containing protein $1 \mathrm{~B}$ gene, is upregulated in various types of cancer, and has been indicated to increase cyclin D1 transcription and enhance cell proliferation by directly interacting with RNA polymerase (RNAP) II (7-12). Recently, CREPT was demonstrated to recognize and interact with RNAP II through the N-terminal RPR domain and C-terminal domain (13). CREPT enhances cell growth and promotes tumorigenesis by promoting the G1- to S-phase transition $(7,14)$. Zhang et al $(15)$ demonstrated that CREPT promotes the expression of cyclin D1 and c-myc through the regulation of Wnt signaling as an underlying mechanism of its oncogenic role to enhance the proliferative and migratory ability of cells. In addition, the expression of CREPT was associated with the survival time of patients with stomach cancer (7). However, to date, the role of CREPT in the development of RCC has remained elusive.

In the present study, the expression of CREPT in RCC tissues was determined by western blot and immunohistochemical (IHC) analyses, and an association between CREPT 
expression and survival rate was revealed. Knockdown of CREPT inhibited the proliferation, colony formation and invasion of RCC cells in vitro. Furthermore, silencing of CREPT was indicated to block the G1- to S-phase cell cycle transition by regulating the expression of c-myc and cyclin D1 in RCC.

\section{Materials and methods}

Patients and tissues. A total of 90 patients with histologically confirmed RCC were analyzed. All of the patients underwent curative radical or partial nephrectomy at the Department of Urology at Peking University People's Hospital (Beijing, China) between July 2010 and January 2014. The freshly obtained tissues were immediately snap-frozen in liquid nitrogen and stored at $-80^{\circ} \mathrm{C}$ for analysis. None of the patients received any adjuvant therapy prior to surgical resection. The clinicopathological characteristics of the patients with RCC are presented in Table I. In the present study, the Tumor-Nodes-Metastasis (TNM) staging system from 2009 was utilized to classify RCC patients (16). Tumor grade was assessed with the Fuhrman four-grade scale (17).

All the patients provided informed consent prior to enrolment in the present study and the protocol was reviewed and approved by the Ethics Committee of Peking University People's Hospital (Beijing, China).

Follow up. After curative surgery, all of the patients were followed up every 6 months until death or recurrence. The median follow up was 23.5 months (range, 8-53 months). The follow up of the 85 patients included in the present study was completed in July 2014.

Histological examination. Samples obtained from the kidney were fixed in $10 \%$ formalin for $24 \mathrm{~h}$ at room temperature and routinely processed for paraffin embedding. Histological sections $(4 \mu \mathrm{m})$ were stained with hematoxylin for $1 \mathrm{~min}$ and eosin for $5 \mathrm{~min}$ at room temperature, and examined by a senior pathologist.

Immunohistochemical analysis. IHC analysis was performed using an IHC polymer double detection kit (OriGene Technologies, Inc., Rockville, MD, USA). In brief, after being deparaffinized and rehydrated, the tissue sections were incubated with $0.3 \%$ hydrogen peroxide for $10 \mathrm{~min}$ to eliminate endogenous peroxidase activity at room temperature. Subsequently, antigen retrieval was performed by heating the sections in $10 \mathrm{mM}$ citrate buffer for $2.5 \mathrm{~min}$. After washing three times with PBS, the sections were incubated with mouse anti-CREPT monoclonal antibody (15) (dilution, 1:100; kindly provided by Dr Zhijie Chang, Tsinghua University, Beijing, China) overnight at $4^{\circ} \mathrm{C}$ in a humidified chamber. After washing three times with PBS, the specimens were incubated with mouse secondary antibody (dilution, 1:200; OriGene Technologies, Inc.) for $30 \mathrm{~min}$ at room temperature. The sections were stained with diaminobenzidine for $50 \mathrm{sec}$ at room temperature and the nuclei were counterstained with Meyer's hematoxylin for $1 \mathrm{~min}$ at room temperature.

IHC evaluation. Nuclear immunoreactivity for CREPT was evaluated using a semi-quantitative method by experienced pathologists who were blinded to the clinicopathological data of the patients. The percentage of positive tumor cells $(0 \%, 0 ; 1-10 \%$, $1 ; 11-50 \%, 2 ; 51-80 \%, 3 ; 81-100 \%, 4)$ and the staining intensity (negative, 0 ; weak, 1; moderate, 2; strong, 3) were evaluated. The numeric values of the two parameters were multiplied to obtain an immunoreactivity score (IRS) ranging from 0 to 12 (18). For statistical analysis, patients were divided into two groups with low or high CREPT expression based on the IRS (IRS $=0-4$ or $6-12$, respectively. The IRS value could not be 5).

Cell culture. The 786-O and 769P human renal cell carcinoma cell lines and the HK-2 normal renal tubular cell line were obtained from the American Type Culture Collection (Manassas, VA, USA) and cultured in RPMI-1640 medium containing 10\% fetal bovine serum (Gibco; Thermo Fisher Scientific, Inc.) at $37^{\circ} \mathrm{C}$ in a $5 \% \mathrm{CO}_{2}$ atmosphere.

CREPT RNA interference. To knock down the expression of CREPT, short hairpin RNA (shRNA) targeting CREPT was used. 786-O and 769P cells were transfected with lentiviral vector containing plasmid pLL3.7-CREPT-short hairpin RNA (pLL3.7-CREPT-sh) or pLL3.7-CREPT-empty vector (pLL3.7-CREPT-EV), respectively. Cells were transfected with lentiviral vector at a MOI of 30 for $48 \mathrm{~h}$ using Lipofectamine ${ }^{\circledR} 3000$ according to the manufacturer's protocol (Invitrogen; Thermo Fisher Scientific, Inc.). The plasmids pLL3.7-CREPT-sh and pLL3.7-CREPT-EV were kindly provided by Dr Zhijie Chang (Tsinghua University, Beijing, China). The sequences of shRNA used were as follows: Forward, 5'-TGGACCTGAATTCACTAGAGATTC AAGAGATCTCTAGTGAATTCAGGTCCTTTTTTC-3' and reverse, 5'-GAAAAAAGGACCTGAATTCACTAGAGATCT CTGGAATCTCTAGTGAATTCAGGTCCA-3'. The underlined sequences represent the 'short inverted repeat sequences' and the sequences between the underlined sequences were the loop of the shRNA. Stably transfected 786-O and 769P cell lines were acquired by screening the lentiviral vector-infected cells with puromycin at a concentration of $2 \mu \mathrm{g} / \mathrm{ml}$ for 2 weeks. The expression of CREPT in the stably transfected cell lines was determined by western blot analysis.

Western blot analysis. Proteins extracted from tissues and cells were extracted using RIPA buffer (Solarbio Life Sciences). Protein quantification were determined using BCA protein assays (Solarbio Life Sciences). A total of $20 \mu \mathrm{g}$ of protein per lane were separated by SDS-PAGE (10\% gel) and transferred onto polyvinylidene fluoride membranes (EMD Millipore, Bedford, MA, USA). Membranes were blocked with $10 \%$ skimmed milk in Tris-buffered saline containing Tween-20 (TBST) for $1 \mathrm{~h}$ at room temperature. Subsequently, the membranes were incubated with primary antibodies overnight at $4^{\circ} \mathrm{C}$. The following primary antibodies were used: Mouse anti-CREPT monoclonal antibody (1:100 dilution; kindly provided by Dr Zhijie Chang) (15); rabbit anti-c-myc monoclonal antibody (1:1,000; cat. no. 5605); rabbit anti-cyclin D1 monoclonal antibody (1:1,000 dilution; cat. no. 2978); and rabbit anti- $\beta$-actin monoclonal antibody (1:2,000 dilution; cat. no. 4970) (all from CST Biological Reagents Co., Ltd.). After three washes with TBST, the membranes were incubated with secondary antibody (goat anti-rabbit IgG H\&L horseradish 
Table I. Relationships between CREPT and features of patients with RCC.

\begin{tabular}{|c|c|c|c|c|c|}
\hline \multirow[b]{2}{*}{ Characteristics } & \multirow[b]{2}{*}{ Number of cases } & \multicolumn{2}{|c|}{ CREPT expression } & \multirow[b]{2}{*}{$\chi^{2}$} & \multirow[b]{2}{*}{ P-value } \\
\hline & & Low & High & & \\
\hline Type & & & & 4.582 & 0.032 \\
\hline Normal & 90 & 62 & 28 & & \\
\hline $\mathrm{RCC}$ & 90 & 48 & 42 & & \\
\hline Fuhrman grade & & & & 15.453 & 0.000 \\
\hline $\mathrm{I}+\mathrm{II}$ & 65 & 43 & 22 & & \\
\hline III & 25 & 5 & 20 & & \\
\hline TNM stage & & & & 11.967 & 0.001 \\
\hline I+II & 65 & 42 & 23 & & \\
\hline $\mathrm{III}+\mathrm{IV}$ & 25 & 6 & 19 & & \\
\hline Sex & & & & 2.087 & 0.149 \\
\hline Male & 55 & 26 & 29 & & \\
\hline Female & 35 & 22 & 13 & & \\
\hline Age (years) & & & & 0.268 & 0.605 \\
\hline$\geq 60$ & 36 & 18 & 18 & & \\
\hline$<60$ & 54 & 30 & 24 & & \\
\hline Size $(\mathrm{cm})$ & & & & 0.179 & 0.673 \\
\hline$\geq 4$ & 45 & 25 & 20 & & \\
\hline$<4$ & 45 & 23 & 22 & & \\
\hline BMI $\left(\mathrm{kg} / \mathrm{m}^{2}\right)$ & & & & 0.658 & 0.417 \\
\hline$\geq 23$ & 50 & 27 & 23 & & \\
\hline$<23$ & 40 & 25 & 15 & & \\
\hline Histological type & & & & 0.097 & 0.756 \\
\hline ccRCC & 76 & 40 & 36 & & \\
\hline Others & 14 & 8 & 6 & & \\
\hline
\end{tabular}

CREPT, cell-cycle-related and expression-elevated protein in tumor; RCC, renal cell carcinoma; TNM, Tumour-Node-Metastasis; ccRCC, clear cell RCC.

peroxidase-conjugated; 1:2,000; cat. no. ab205718 or goat anti-rabbit IgG H\&L horseradish peroxidase-conjugated; 1:2,000; ab205719; Abcam) at $37^{\circ} \mathrm{C}$ for $1 \mathrm{~h}$ and then washed with TBST five times prior to exposure. Quantitative analysis of protein expression was assessed via measurement of the gray value of each protein band using ImageJ v1.8.0, (National Institutes of Health, Bethesda, MD, USA). $\beta$-actin was used as the loading control.

Cell Counting Kit (CCK)-8 assay. Cell proliferation was examined using a CCK- 8 assay. A total of $1.5 \times 10^{3} 786-\mathrm{O}$ or 769P cells stably transfected with CREPT-EV or CREPT-sh in $100 \mu \mathrm{l}$ complete medium were individually seeded in 96-well plates with three repeats per condition. At different time-points, $10 \mu \mathrm{l}$ CCK- 8 stain was added into each well, followed by incubation for $1.5 \mathrm{~h}$ prior to measurement of the absorbance at $450 \mathrm{~nm}$.

Colony formation assay. The 786-O and 769P cells stably transfected with CREPT-EV or CREPT-sh were individually seeded into 6-well plates at a density of 1,000 cells/well.
After culturing at $37^{\circ} \mathrm{C}$ for two weeks, the cells were stained with $0.1 \%$ crystal violet for $10 \mathrm{~min}$ at room temperature. Subsequently, the cells were washed three times with PBS and the number of clones were counted.

Wound-healing assay. The in vitro wound-healing assay was performed as described previously (19). The cells were seeded in 6-well plates to generate a confluent monolayer. The monolayer was scratched with a sterile $200-\mu$ l pipette tip and the floating cells were carefully removed by rinsing with PBS. The cells were cultured in RPMI-1640 medium without FBS at $37^{\circ} \mathrm{C}$ in an atmosphere containing $5 \% \mathrm{CO}_{2}$. Images of the wounds were captured at 0 and $48 \mathrm{~h}$ after scraping. The sizes of the wound closure areas were analyzed using Image-Pro plus 6.0 (Media Cybernetics, Inc., Rockville, MA, USA).

Cell invasion assay. The cell invasion assays were performed using Matrigel Invasion Chambers with a pore size of $8 \mu \mathrm{m}$ (Corning, Inc., Corning, NY, USA). A total of $3 \times 10^{4} 786-\mathrm{O}$ and 769P cells in $300 \mu \mathrm{l}$ serum-free medium were seeded into the upper chamber, and $600 \mu 1$ supplemented medium was 
added to the bottom of the chamber. After culturing for $24 \mathrm{~h}$, the cells that passed through the membrane were fixed with 4\% paraformaldehyde for $20 \mathrm{~min}$ at room temperature and subsequently stained with crystal violet for $20 \mathrm{~min}$ at room temperature. The cells on the upper surface of the chamber were wiped off and after washing with PBS, the invaded cells were counted in five random fields under a microscope. All the assays were performed three times.

Flow cytometry and cell cycle analysis. Cells were collected and washed with ice-cold PBS. The cell cycle was determined by flow cytometry (Beckman Coulter, Brea, CA, USA) after staining with propidium iodide (Liankenbio, Hangzhou, China) according to the manufacturer's protocols. The data was analyzed using CytExpert software (version 2.0; Beckman Coulter, Inc.).

Statistical analysis. All experiments were performed at least three times and the values are expressed as the mean \pm standard deviation. The statistical significance between the migration and invasion of cells in different groups was analyzed with a Student's t-test. One-way analysis of variance and a Dunnett's Multiple Comparison post-hoc test were used to analyze the expression of CREPT in the cell lines. Differences in the cell cycle distribution and differences of protein expression in different groups were analyzed using two-way analysis of variance, and Bonferroni post-hoc test was used to determine these differences. The statistical analyses for clinical samples were performed using the SPSS software 19.0 (IBM Corp., Armonk, NY, USA). The $\chi^{2}$ test and Fisher's exact test were used to analyze the association between CREPT expression measured by immunohistochemistry and the clinicopathological characteristics of RCC. Survival analyses were performed via drawing Kaplan-Meier curves, and the differences between subgroups were analyzed using the log-rank test. $\mathrm{P}<0.05$ was considered to indicate a statistically significant difference.

\section{Results}

CREPT is overexpressed in RCC tissues and cell lines. To investigate CREPT expression in RCC, the protein expression was first assessed in seven pairs of RCC and matched adjacent tissues through western blot analysis. CREPT was overexpressed in four of the seven pairs of tissue samples (Fig. 1A). Furthermore, IHC staining for CREPT was performed on 90 RCC samples. CREPT staining was detected in the nuclei of tumor cells, but not in the cytoplasm (Fig. 1B). Quantification of the staining indicated that the expression of CREPT in tumor tissues was increased in 65\% (58/90), unchanged in 33\% (30/90) and decreased in $2 \%(2 / 90)$ of the samples compared with that in adjacent normal renal tissues (Fig. 1B and C). CREPT expression was then examined via western blot analysis in RCC cell lines, 786-O and 769P, and a normal renal tubular cell line, HK-2. As presented in Fig. 1D, CREPT expression was increased in 786-O and 769P cells, and considerably lower in HK-2. Taken together, CREPT was overexpressed in RCC.

Association between CREPT expression and clinicopathological characteristics of patients with RCC. As presented in Table I, the expression of CREPT in RCC tissues was increased compared with normal tissues $(\mathrm{P}=0.032)$, and was significantly associated with the TNM stage $(\mathrm{P}=0.001)$ and Fuhrman grade $(\mathrm{P}<0.001)$. However, there were no significant associations identified between CREPT expression and sex $(\mathrm{P}=0.149)$, age $(\mathrm{P}=0.605)$, tumor size $(\mathrm{P}=0.673)$, body mass index $(\mathrm{P}=0.417)$ and histological type $(\mathrm{P}=0.756)$. Furthermore, survival analysis was performed for 85 of the patients. The 85 patients were stratified into two groups according to the expression levels of CREPT (high or low). The high CREPT expression group comprised 38 patients, of whom 11 had recurrence or metastasis, and 7 cases died of recurrence. The remaining 47 patients had relatively lower levels of CREPT expression, among whom 3 cases had recurrence or metastasis and only one patient died of recurrence. The Kaplan-Meier analysis revealed that patients with increased CREPT expression had significantly worse overall survival rates $(\mathrm{P}=0.021$; Fig. 1E) and disease-free survival rates $(P=0.015$; Fig. 1E) compared with patients with low CREPT expression levels. Together, these data indicate that CREPT is a powerful prognostic factor for overall survival and disease-free survival of patients with RCC.

Knockdown of CREPT inhibits the proliferation and colony formation of RCC cells. siRNA-mediated knockdown was performed to evaluate the effect of CREPT on the biological behavior of RCC cells,. By using western blot analysis, it was confirmed that the expression levels of CREPT in the RCC cells transfected with CREPT-sh were significantly lower compared with those in cells transfected with CREPT-EV (Fig. 2A). The effect of CREPT knockdown on the proliferation of RCC cells was then assessed using CCK-8 assays. As presented in Fig. 2B, the proliferation of 786-O and 769P cells stably transfected with CREPT-sh was significantly decreased from day 3 onwards compared with cells transfected with CREPT-EV. Furthermore, the effect of CREPT on the colony formation ability was evaluated using clonogenic assays. After knocking down CREPT expression in 786-O and 769P cells, the number and size of the colonies was significantly decreased in both 786-O cells $(\mathrm{P}<0.01)$ and for 769P cells $(\mathrm{P}<0.001$; Fig. 2C). Taken together, these results suggest that CREPT is involved in regulating the proliferation and colony formation of RCC cells.

Knockdown of CREPT induces cell cycle arrest at the G1 phase. Effect of CREPT on the cell cycle was examined by flow cytometric analysis. The results suggested that silencing of CREPT in 786-O or 769P cells resulted in G1 arrest (Fig. 2D).

Furthermore, knockdown of CREPT led to a decrease in the expression of cyclin D1. Considering that c-myc and cyclin D1 are key regulators of the cell cycle, the protein expression levels of c-myc and cyclin D1 in stably transfected 786-O or $769 \mathrm{P}$ cells were assessed via western blot analysis. The results indicated that the expression levels of cyclin D1 and c-myc were markedly decreased in CREPT-sh cells compared with those in CREPT-EV cells (Fig. 2E).

Silencing of CREPT inhibits the migration and invasion of $R C C$ cells. To evaluate the effect of CREPT on the metastatic 
A
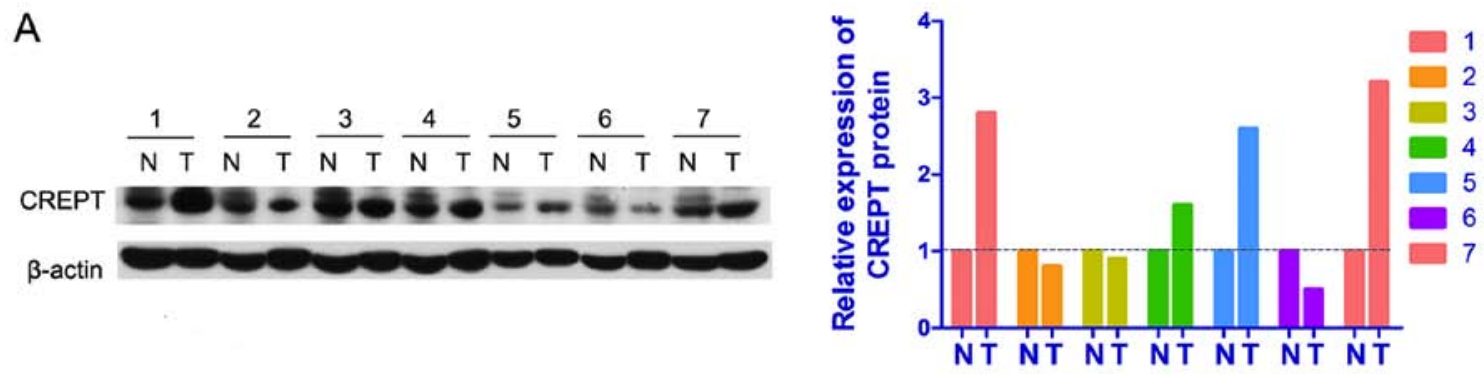

B High expression

Low expression

Negative staining
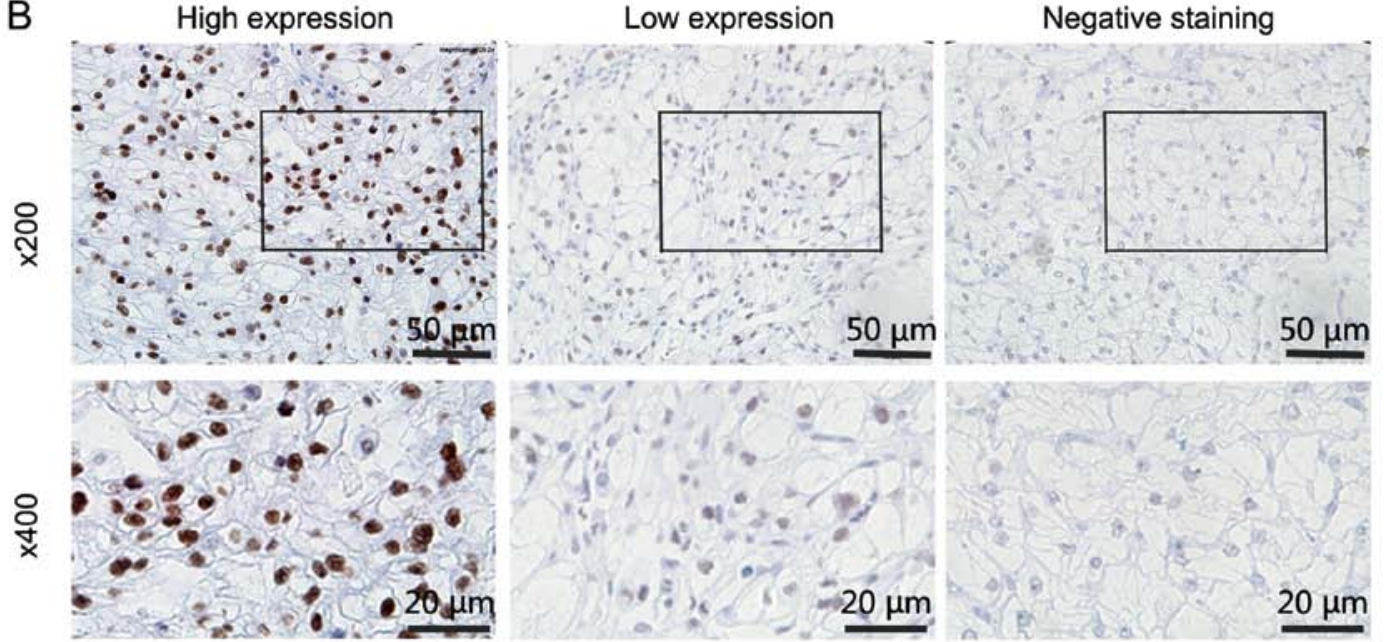

C

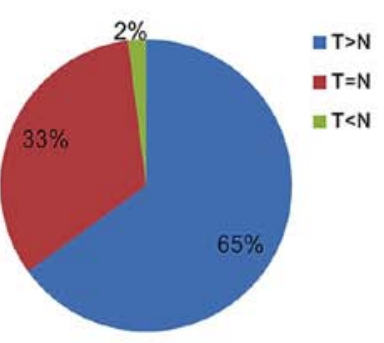

D

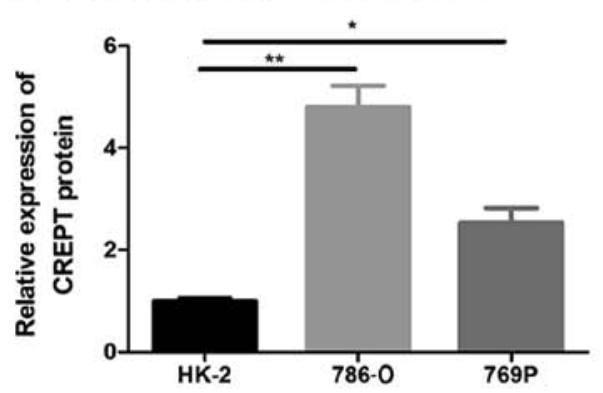

$\mathrm{E}$
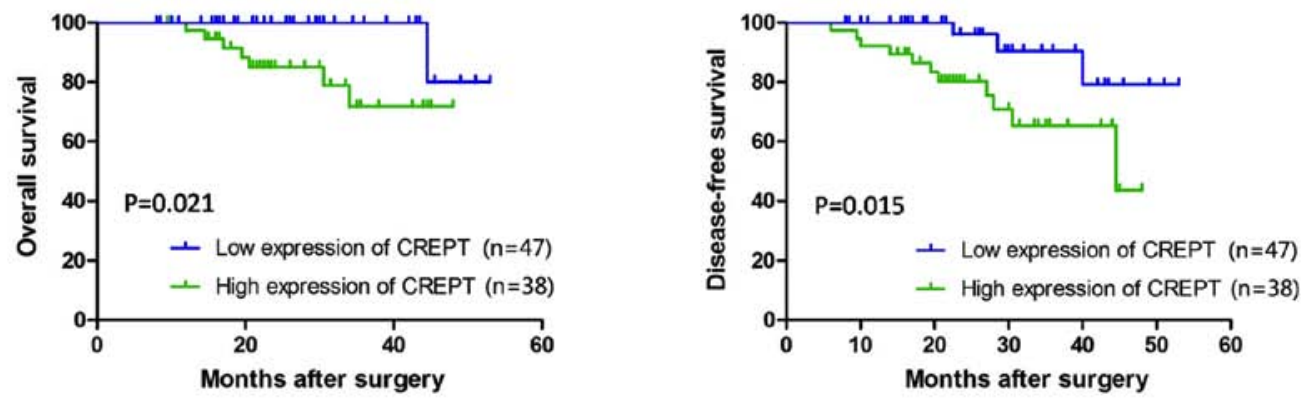

Figure 1. CREPT is upregulated in RCC tissues and associated with the prognosis of patients with RCC. (A) Upregulated expression of CREPT protein was observed in 4 out of 7 patients with RCC when compared with paired normal renal tissues by western blot analysis. (B) CREPT was overexpressed in RCC tissues and was primarily located in the nuclei of tumor cells according to the results of the IHC analysis. (C) Pie chart of the distribution of CREPT expression in 90 tumor tissues compared with the paired adjacent normal renal tissues by IHC. T $>\mathrm{N}$, the expression levels of CREPT were increased in tumor tissues; T=N, the expression levels of CREPT were unchanged; $\mathrm{T}<\mathrm{N}$, the expression levels of CREPT were decreased. (D) Western blot analysis indicated that the expression levels of CREPT in RCC cell lines were higher than those in the HK-2 normal kidney cell line (left). The statistical analysis of CREPT protein expression in 786-O and 769P cells compared with that in HK-2 cells (right) (E) Association between CREPT expression and overall survival or disease-free survival of patients with RCC by Kaplan-Meier analysis. ${ }^{*} \mathrm{P}<0.05,{ }^{* *} \mathrm{P}<0.01$. T, tumor tissue; N, normal tissue; RCC, renal cell carcinoma; CREPT, cell-cycle-related and expression-elevated protein in tumor; IHC, immunohistochemistry.

ability of RCC cells, the two stably transfected cell lines were subjected to wound healing and invasion assays. Of note, downregulation of CREPT significantly reduced the migration rate and the number of invaded 7860 or $769 \mathrm{p}$ cells (Fig. 3A and B).

\section{Discussion}

Although clinical treatment strategies and preliminary health checks have improved in recent years, the prognosis for patients with RCC remains unsatisfactory, which is partly due to the high 
A

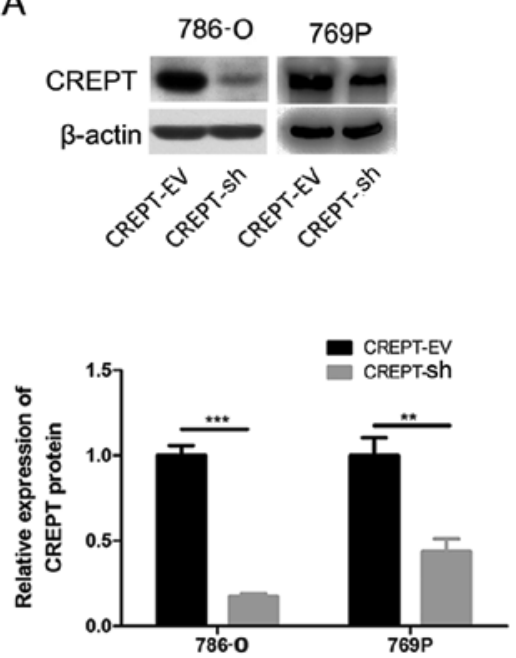

$\mathrm{D}$
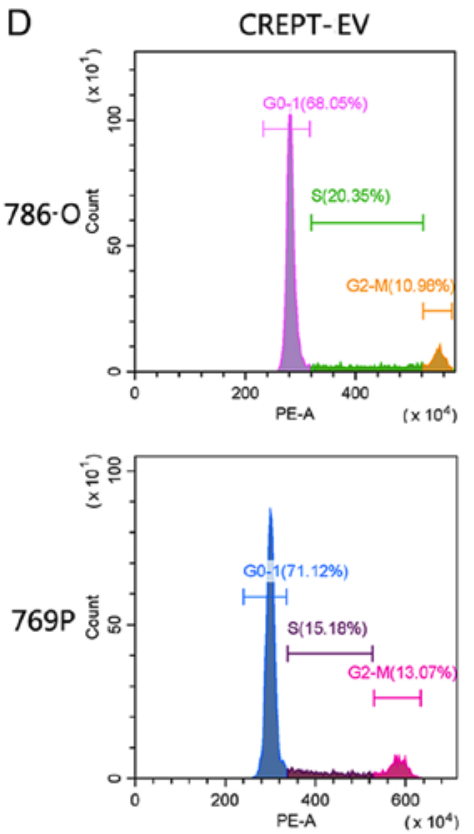

E

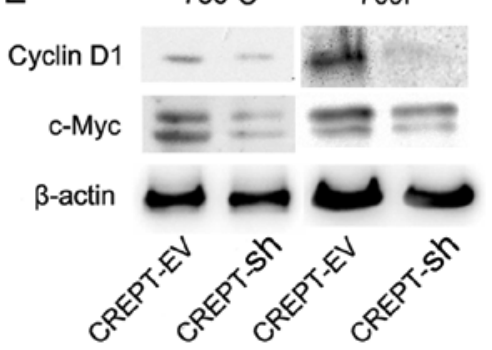

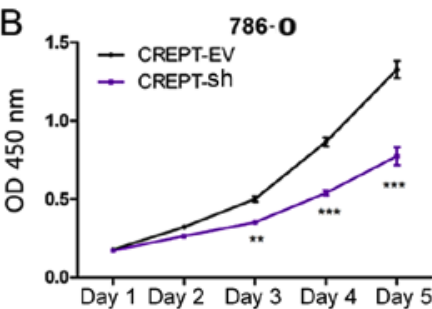

769P
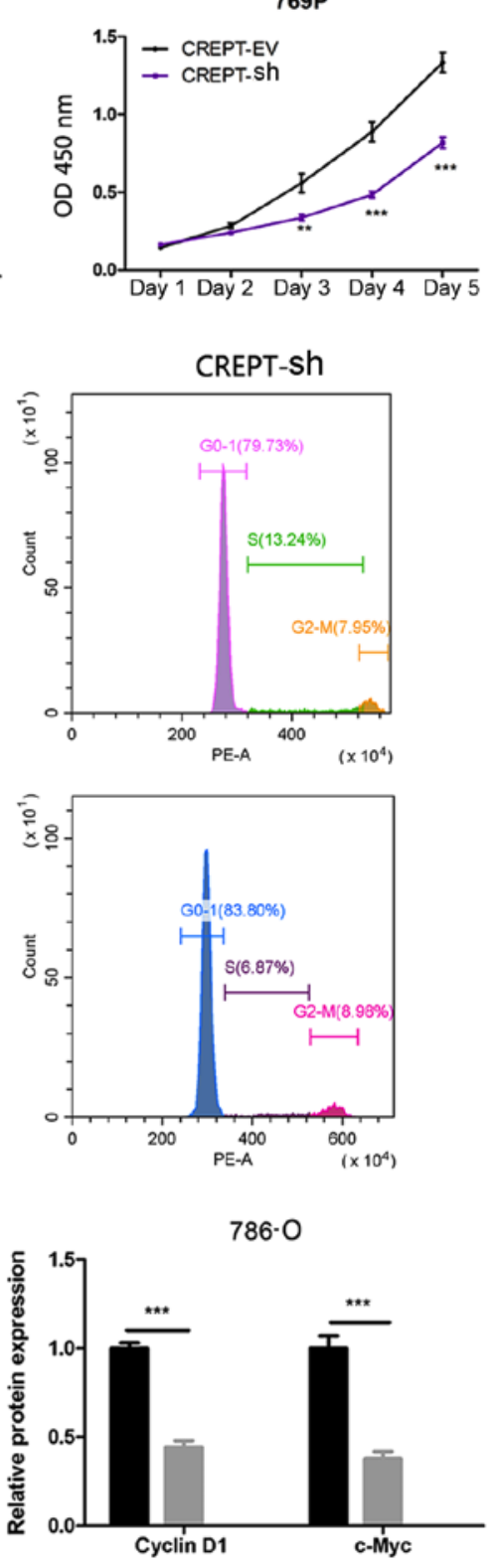
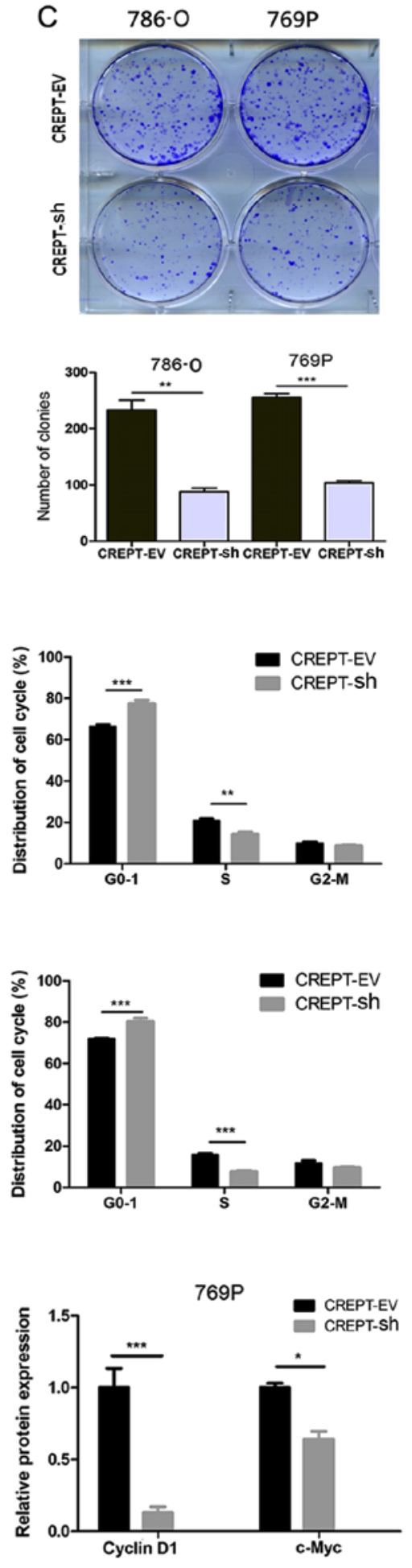

Figure 2. Roles of CREPT in renal cell carcinoma cells. (A) Western blot analysis and densitometry analysis indicated that the expression levels of CREPT were significantly decreased in the CREPT-sh-infected cell lines compared with the control cells transfected with CREPT-EV. (B) Cells transfected with CREPT-sh grew slower compared with the control cells transfected with CREPT-EV. (C) Colony formation by cells transfected with CREPT-sh was reduced compared with the control cells transfected with CREPT-EV. (D) Percentage of cells in G1 phase of the cell cycle in the CREPT-sh group was significantly higher compared with the control cells transfected with CREPT-EV. (E) Western blot analysis (left) and densitometry analysis (right) indicated that the expression of cyclin D1 and c-myc was decreased following CREPT depletion. CREPT-sh, shRNA specifc for cell-cycle-related and expression-elevated protein in tumor; CREPT-EV, empty vector. ${ }^{*} \mathrm{P}<0.05,{ }^{* *} \mathrm{P}<0.01$ and ${ }^{* * * *} \mathrm{P}<0.0001$. G0-1, G0 and G1 phase in cell cycle; $\mathrm{S}, \mathrm{S}$ phase in cell cycle; G2-M, G2 and M phase in cell cycle; PE, phycoerythrin; PE-A, area of detected signal in PE channel.

rate of recurrence and distant metastasis. At present, the established TNM staging and Fuhrman grading systems are used as prognostic indicators for RCC (20-22). Our understanding of the pathogenesis of RCC has increased in recent years, and various 

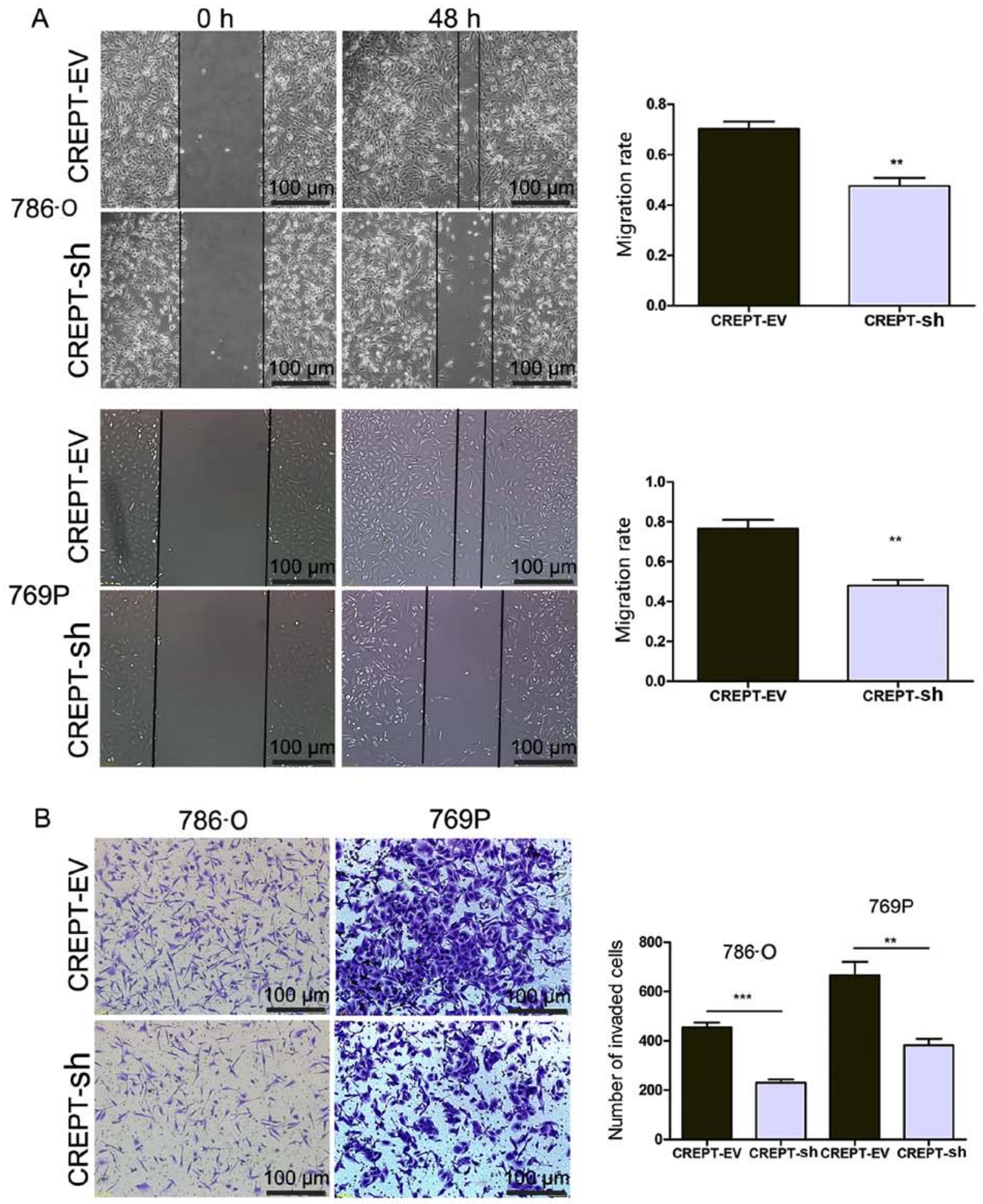

Figure 3. Silencing of CREPT inhibits the migration and invasion of renal cell carcinoma cells. (A) Wound-healing assays revealed that CREPT-shlenced cells had a lower motility compared with that of the control-transfected cells. (B) Number of invaded cells in the CREPT-sh group was lower than that in the CREPT-EV group. ${ }^{* *} \mathrm{P}<0.01$ and ${ }^{* * * *} \mathrm{P}<0.001$. CREPT-sh, shRNA specific for cell-cycle-related and expression-elevated protein in tumor; CREPT-EV, empty vector. CREPT, cell-cycle-related and expression-elevated protein in tumor; sh, short hairpin; EV, empty vector.

prognostic indicators of RCC progression have been identified, including the expression levels of leucine zipper-EF-hand containing transmembrane protein 1 , lactate dehydrogenase and microRNAs (miRs) (23-26). However, there is still a lack of reliable biomarkers for predicting RCC progression and monitoring the response to drug treatment. In particular, patients with the same TNM stage and/or Fuhrman grade of RCC have a high variability in disease recurrence and metastasis. Therefore, novel biomarkers with the ability to effectively predict differential prognoses for patients with the same TNM stage and/or 
Fuhrman grade are required. It is desirable to identify novel molecular markers associated with the progression of RCC, which may also be of great significance for the improvement of therapeutic strategies and patient prognosis.

Previous findings have shown the upregulation of CREPT in various tumors and studied the role it serves in tumorigenesis and disease progression. In colorectal cancer, CREPT upregulation is involved in cell proliferation and is directly controlled by miR-383 through targeting the 3'-untranslated region of the CREPT gene (27). Additionally, upregulation of CREPT was associated with histological grade of colorectal cancer and was involved in conferring sensitivity of colorectal cancer cells to 5-fluorouracil treatment (28). Consistent with the expression of CREPT in colorectal cancer, the results of the present study confirmed that CREPT protein was localized to the nuclear region of RCC cells, and that the expression levels of CREPT were significantly higher in RCC tissues compared with those in normal adjacent tissues. Furthermore, CREPT expression was associated with the TNM stage and Fuhrman grade of RCC, but not with sex, age, tumor size and histological type of patients with RCC, which indicated that overexpression of CREPT is a major promoter of the development and progression of RCC. In addition, it was indicated that patients with increased CREPT expression had a significantly lower overall and disease-free survival rate than those with low CREPT expression. Therefore, CREPT may be a negative prognosticator for RCC.

In the present in vitro study, the effects of CREPT on RCC cells were assessed through silencing of CREPT in RCC cell lines (786-O and 769P). The results indicated that the proliferation, colony formation, migration and invasion of 786-O and 769P cells were significantly suppressed after knockdown of CREPT. Therefore, CREPT may be used as a novel marker to identify malignant progression in patients with RCC.

The dysregulation of the cell cycle is a common phenomenon in almost all types of human cancer (29-31). In the present study, it was indicated that silencing of CREPT resulted in cell cycle arrest at G1 phase, which may explain the inhibitory effect of CREPT on the proliferation of RCC cells. Cyclin D1, a cell cycle regulator, was confirmed to have a critical role in the initiation and progression of $\operatorname{RCC}(32,33)$. Dysfunction or abnormal expression of numerous regulatory genes may cause the development of cancer through upregulating the expression of cyclin D1 (33). In gastric cancer, silencing of CREPT suppressed cell proliferation through the induction of G0/G1 phase cell cycle arrest via reducing the expression of cyclin D1 and Cyclin D-dependent kinase 4, and inducing the expression of p53 and p21 (34). Consistent with the findings in gastric cancer, the present results indicated that cyclin D1 may be regulated by CREPT in RCC. C-myc is also a key regulator of the cell cycle and may be regulated by CREPT through the Wnt signaling pathway (15). In the present study, CREPT was demonstrated to decrease the expression of c-myc and promote the progression of RCC. However, no evidence for CREPT regulating the expression of cyclin D1 and c-myc directly was provided. Further investigation of the underlying mechanisms of CREPT-mediated regulation of cyclin D1 and c-Myc is required. Furthermore, previous studies have revealed that CREPT may be regulated by miR-383 in colorectal cancer, and influences the sensitivity of colorectal cancer to fluorouracil, as well as gastric cancer cell apoptosis $(27,28,34)$, indicating a pleiotropic effect of CREPT on various cancer types and complex mechanisms by which CREPT promotes tumor progression. Therefore, further studies are required in order to elucidate the potential molecular mechanisms underlying CREPT in promoting tumor progression. .

In conclusion, the present study is the first to report that CREPT is significantly overexpressed in RCC and is associated with the TNM stage, Fuhrman grade and prognosis of patients with RCC, to the best of the our knowledge. Knockdown of CREPT suppressed RCC cell growth, colony formation and invasion, and caused cell cycle arrest through restraining the expression of cyclin D1 and c-myc. Thus, CREPT may be a promising novel prognostic marker and a potential target for the treatment of RCC.

\section{Acknowledgements}

Not applicable.

\section{Funding}

The present study was funded by The Fund for Fostering Young Scholars of Peking University Health Science Center (grant no. BMU2018PY012) and The Fund for Beijing Municipal Health Commission (grant no. 2127000132).

\section{Availability of data and materials}

The datasets used and/or analyzed during the current study are available from the corresponding author on reasonable request.

\section{Authors' contributions}

HQY and QFC performed the experiments and drafted the manuscript. HYZ participated in the interpretation of data and revision of manuscript. SHW and WNC were involved in the acquisition and analysis of data. XWZ contributed to collecting specimen used in this study. ZJC conceived of the study. TX and XJY participated in the design of the study.

\section{Ethics approval and consent to participate}

The protocol utilized in the present study was reviewed and approved by The Ethics Committee of Peking University People's Hospital (Beijing, China). All patients provided informed consent prior to enrolment in the present study.

\section{Patient consent for publication}

Not applicable.

\section{Competing interests}

The authors have no conflict of interests to declare.

\section{References}

1. Matsuura K, Nakada C, Mashio M, Narimatsu T, Yoshimoto T, Tanigawa M, Tsukamoto Y, Hijiya N, Takeuchi I, Nomura T, et al: Downregulation of SAV1 plays a role in pathogenesis of high-grade clear cell renal cell carcinoma. BMC Cancer 11: 523, 2011. 
2. Miyamoto H, Miller JS, Fajardo DA, Lee TK, Netto GJ and Epstein JI: Non-invasive papillary urothelial neoplasms: The 2004 WHO/ISUP classification system. Pathol Int 60: 1-8, 2010.

3. Montironi R, Santinelli A, Pomante R, Mazzucchelli R, Colanzi P, Filho AL and Scarpelli M: Morphometric index of adult renal cell carcinoma. Comparison with the Fuhrman grading system. Virchows Arch 437: 82-89, 2000.

4. Cindolo L, Patard JJ, Chiodini P, Schips L, Ficarra V, Tostain J, de La Taille A, Altieri V, Lobel B,Zigeuner RE, et al: Comparison of predictive accuracy of four prognostic models for nonmetastatic renal cell carcinoma after nephrectomy: A multicenter European study. Cancer 104: 1362-1371, 2005.

5. Jiang Z, Chu PG, Woda BA, Liu Q, Balaji KC, Rock KL and Wu CL: Combination of quantitative IMP3 and tumor stage: A new system to predict metastasis for patients with localized renal cell carcinomas. Clin Cancer Res 14: 5579-5584, 2008.

6. Kim SP, Alt AL, Weight CJ, Costello BA, Cheville JC, Lohse C, Allmer C and Leibovich BC: Independent validation of the 2010 American Joint Committee On Cancer TNM classification for renal cell carcinoma: Results from a large, single institution cohort. J Urol 185: 2035-2039, 2011.

7. Lu D, Wu Y, Wang Y, Ren F, Wang D, Su F, Zhang Y, Yang X, Jin $\mathrm{G}$, Hao $\mathrm{X}$, et al: CREPT accelerates tumorigenesis by regulating the transcription of cell-cycle-related genes. Cancer Cell 21: 92-104, 2012.

8. Ma J, Ren Y, Zhang L, Kong X, Wang T, Shi Y and Bu R Knocking-down of CREPT prohibits the progression of oral squamous cell carcinoma and suppresses cyclin D1 and c-Myc expression. PLos One 12: e174309, 2017.

9. Liang Z, Feng Q, Xu L, Li S and Zhou L: CREPT regulated by miR-138 promotes breast cancer progression. Biochem Biophys Res Commun 493: 263-269, 2017.

10. Zheng G, Li W, Zuo B, Guo Z, Xi W, Wei M, Chen P, Wen W and Yang AG: High expression of CREPT promotes tumor growth and is correlated with poor prognosis in colorectal cancer. Biochem Biophys Res Commun 480: 436-442, 2016.

11. Liu T, Li WM, Wang WP, Sun Y, Ni YF, Xing H, Xia JH, Wang XJ, Zhang ZP and Li XF: Inhibiting CREPT reduces the proliferation and migration of non-small cell lung cancer cells by down-regulating cell cycle related protein. Am J Transl Res 8 : 2097-2113, 2016.

12. Ren F, Wang R, Zhang Y, Liu C, Wang Y, Hu J, Zhang L and Chang Z: Characterization of a monoclonal antibody against CREPT, a novel protein highly expressed in tumors. Monoclon Antib Immunodiagn Immunother 33: 401-408, 2014.

13. Mei K, Jin Z, Ren F, Wang Y, Chang Z and Wang X: Structural basis for the recognition of RNA polymerase II C-terminal domain by CREPT and p15RS. Sci China Life Sci 57: 97-106, 2014.

14. Wang Y, Qiu H, Hu W, Li S and Yu J: RPRD1B promotes tumor growth by accelerating the cell cycle in endometrial cancer. Oncol Rep 31: 1389-1395, 2014.

15. Zhang Y, Liu C, Duan X, Ren F, Li S, Jin Z, Wang Y, Feng Y, Liu $Z$ and Chang Z: CREPT/RPRD1B, a recently identified novel protein highly expressed in tumors, enhances the $\beta$-catenin. TCF4 transcriptional activity in response to Wnt signaling. J Biol Chem 289: 22589-22599, 2014

16. Fisseler-Eckhoff A: New TNM classification of malignant lung tumors 2009 from a pathology perspective. Pathologe 30 (Suppl 2): S193-S199, 2009 (In German).

17. Fuhrman SA, Lasky LC and Limas C: Prognostic significance of morphologic parameters in renal cell carcinoma. Am J Surg Pathol 6: 655-663, 1982.
18. Sinn BV, von Minckwitz G, Denkert C, Eidtmann $H$, Darb-Esfahani S, Tesch H, Kronenwett R, Hoffmann G, Belau A, Thommsen C, et al: Evaluation of Mucin-1 protein and mRNA expression as prognostic and predictive markers after neoadjuvant chemotherapy for breast cancer. Ann Oncol 24: 2316-2324, 2013.

19. Liang CC, Park AY and Guan JL: In vitro scratch assay: A convenient and inexpensive method for analysis of cell migration in vitro. Nat Protoc 2: 329-333, 2007.

20. Edge SB and Compton CC: The American Joint Committee on Cancer: The 7th edition of the AJCC cancer staging manual and the future of TNM. Ann Surg Oncol 17: 1471-1474, 2010.

21. Delahunt B, Sika-Paotonu D, Bethwaite PB, William Jordan T, Magi-Galluzzi C, Zhou M, Samaratunga H and Srigley JR: Grading of clear cell renal cell carcinoma should be based on nucleolar prominence. Am J Surg Pathol 35: 1134-1139, 2011.

22. Erdoğan F, Demirel A and Polat O: Prognostic significance of morphologic parameters in renal cell carcinoma. Int J Clin Pract 58: 333-336, 2004

23. Xu J, Huang B, Li S, Zhang X, Xie T and Xu Y: Knockdown of LETM1 inhibits proliferation and metastasis of human renal cell carcinoma cells. Oncol Lett 16: 6377-6382, 2018.

24. Wang Y, Li G, Wan F, Dai B and Ye D: Prognostic value of D-lactate dehydrogenase in patients with clear cell renal cell carcinoma. Oncol Lett 16: 866-874, 2018.

25. Chen P, Zhao L, Pan X, Jin L, Lin C, Xu W, Xu J, Guan X, Wu X, Wang Y, et al: Tumor suppressor microRNA-136-5p regulates the cellular function of renal cell carcinoma. Oncol Lett 15: 5995-6002, 2018.

26. Zhang XL, Xu G, Zhou Y and Yan JJ: MicroRNA-183 promotes the proliferation and metastasis of renal cell carcinoma through targeting Dickkopf-related protein 3. Oncol Lett 15: 6003-6008, 2018.

27. Li J, Smith AR, Marquez RT, Li J, Li K, Lan L, Wu X, Zhao L, Ren F, Wang Y, et al: MicroRNA-383 acts as a tumor suppressor in colorectal cancer by modulating CREPT/RPRD1B expression. Mol Carcinog 57: 1408-1420, 2018.

28. Kuang YS, Wang Y, Ding LD, Yang L, Wang Y, Liu SH, Zhu BT, Wang XN, Liu HY, Li J, et al: Overexpression of CREPT confers colorectal cancer sensitivity to fluorouracil. World J Gastroenterol 24: 475-483, 2018.

29. Kim JK and Diehl JA: Nuclear cyclin D1: An oncogenic driver in human cancer. J Cell Physiol 220: 292-296, 2009.

30. Nojima H: G1 and S-phase checkpoints, chromosome instability, and cancer. Methods Mol Biol 280: 3-49, 2004.

31. Massague J: G1 cell-cycle control and cancer. Nature 432: 298-306, 2004

32. Liu Z, Fu Q, Lv J, Wang F and Ding K: Prognostic implication of p27Kip1, Skp2 and Cks1 expression in renal cell carcinoma: A tissue microarray study. J Exp Clin Cancer Res 27: 51, 2008.

33. Lima MS, Pereira RA, Costa RS, Tucci S, Dantas M, Muglia VF, Ravinal RC and Barros-Silva GE: The prognostic value of cyclin D1 in renal cell carcinoma. Int Urol Nephrol 46: 905-913, 2014.

34. Sun M, Si G, Sun HS and Si FC: Inhibition of CREPT restrains gastric cancer growth by regulation of cycle arrest, migration and apoptosis via ROS-regulated p53 pathway. Biochem Biophys Res Commun 496: 1183-1190, 2018.

(i) $($ This work is licensed under a Creative Commons Attribution-NonCommercial-NoDerivatives 4.0 International (CC BY-NC-ND 4.0) License. 